\title{
An Examination of the Validity of the Differentiation-of-Self Hypothesis and Its Mechanism Related to Negative Life Event Aversion among Japanese University Students
}

\author{
Koji Kudo \\ Department of Educational Psychology, Tokyo Gakugei University, Tokyo, Japan \\ Email:kojikudo@u-gakugei.ac.jp
}

How to cite this paper: Kudo, K. (2020) An Examination of the Validity of the Differentiation-of-Self Hypothesis and Its Mechanism Related to Negative Life Event Aversion among Japanese University Students. Open Journal of Medical Psychology, 9, 89-99.

https://doi.org/10.4236/ojmp.2020.93008

Received: April 1, 2020

Accepted: May 23, 2020

Published: May 26, 2020

Copyright $\odot 2020$ by author(s) and Scientific Research Publishing Inc. This work is licensed under the Creative Commons Attribution International License (CC BY-NC 4.0).

http://creativecommons.org/licenses/by/4.0/

c) (i) \&) Open Access

\begin{abstract}
This study examined the validity of the differentiation-of-self hypothesis for Japanese university students, and its mechanism in relation to negative life event aversion. Although the differentiation-of-self hypothesis is accepted as one of the basic hypotheses in the clinical field of family therapy in Japan, empirical studies on the subject are scarce. Further, there are few studies, internationally, on its mechanism. A questionnaire survey was conducted with university students $(n=250)$ to measure their differentiation of self, maladaptive states, and negative life event aversion. Compared to the better-differentiated group, the less-differentiated group had higher scores both for maladaptive states-somatic symptoms $(t(223)=-2.70, p=0.008)$, social dysfunction $(t(211.00)=-3.30, p=0.001)$, and severe depression $(t(208.78)=-4.08, p<$ $0.001)$ - and negative life event aversion-interpersonal domain $(t(223)=$ $-3.96, p<0.001)$ and achievement domain $(t(223)=-3.83, p<0.001)$. The results supported the validity of the differentiation-of-self hypothesis for Japanese university students, and that cognitive tendencies toward negative life events may be part of the mechanism for less-differentiated individuals' subsequent vulnerability. This suggests the effectiveness of cognitive interventions.
\end{abstract}

\section{Keywords}

Differentiation of Self, Validity, Negative Life Events, Vulnerability, Aversion

\section{Introduction}

\subsection{Differentiation-of-Self Hypothesis}

Differentiation of self [1] is a fundamental concept in the field of family therapy 
based on system theory [2]. It comprises two domains: differentiation in the intrapsychic domain and differentiation in the interpersonal domain. Intrapsychic differentiation is the balance between thoughts and emotions, and interpersonal differentiation is the balance between the desire for individuality and togetherness in interpersonal relationships. Individuals who are less differentiated in the intrapsychic domain are likely to be excessively emotional. Individuals who are less differentiated in the interpersonal domain are likely to strongly desire togetherness. According to Bowen [1] [3], individuals with less differentiation are vulnerable to negative life events. This is called the differentiation-of-self hypothesis. To date, a number of empirical studies have been conducted on self-differentiation [4] [5] [6] [7].

The concept of the differentiation of self is closely related to adolescence because its development depends on the degree of emotional separation from one's family of origin. As Havighurst [8] pointed out, this separation is one of the major developmental challenges of adolescence. Therefore, the differentiation-ofself hypothesis is an important consideration in ameliorating adolescents' vulnerability to negative life events.

\subsection{Mechanism of Less-Differentiated Individuals' Negative Life Event Vulnerability}

There are few empirical studies on why people with low differentiation of self are vulnerable to negative life events. Although many studies have shown that, typically, individuals with less differentiation exhibit some form of maladaptation, few have examined the underlying mechanism. Previous literature [1] does not explain it in detail, and clarifying this mechanism is crucial in considering clinical interventions for less-differentiated individuals. According to Kerr and Bowen [3], degrees of self-differentiation are determined by a multigenerational transmission process. Based on this concept, psychotherapy can improve degrees of self-differentiation, but only over the long term [9]. In other words, to fundamentally improve the low levels of self-differentiation that engender vulnerability to negative life events, an individual's relationships with previous generations require review, potentially over several years.

By comparison, building personal characteristics that improve resilience to negative life events can happen quickly. One framework to which this idea can be applied is Lazarus and Folkman's [10] psychological stress process, which states the significance of recognizing how to cope with negative life events. From this perspective, people with low differentiation of self tend to regard events more negatively or inappropriately respond to events and, as a result, they tend to fall into maladaptive states. According to Yusa [9], less-differentiated individuals tend to be unrealistic in their evaluations of others. More than better-differentiated individuals, they evaluate negative life events as more aversive, especially in the interpersonal domain. Therefore, they are prone to maladaptive states. If this is a valid explanation of the mechanism behind negative life event vulnerability in people with low differentiation of self, then resilience can be 
built by improving their cognition or coping skills. This can be done in relatively short span of time, compared to fundamentally improving their differentiation of self.

\subsection{Literature on Differentiation of Self in Japan}

In Japan, the differentiation-of-self hypothesis is accepted as one of the basic hypotheses in the clinical field of family therapy. However, unlike overseas, the number of Japanese empirical studies on this topic is limited.

Currently, there are some studies on differentiation of self in high school students. For example, Kudo and Fujiu [11] elucidated the mechanism of the differentiation-of-self hypothesis among high school students by focusing on degrees of subjective negative life event aversion, in line with the above-described framework [10]. Their study showed that differentiation of self has a negative effect on negative life event aversion. In other words, less differentiation causes greater negative life event aversion. In Lazarus and Folkman's [10] framework, the evaluation of negative life event aversion corresponds to the primary appraisal. Therefore, this suggests that individuals with low differentiation of self have a worse perception of negative life events at the primary appraisal stage, which increases these events' negative influence, and the possibility of maladaptation. The study also showed that aversiveness of negative life events is more associated with differentiation of self in the interpersonal domain, rather than in the achievement domain. Thus, individuals who have low differentiation of self tend to be unrealistic in evaluating others [9]. For this reason, increasing aversiveness of negative life events is more likely in the interpersonal domain than in the achievement domain [11].

However, the results included evaluations of negative life event aversion that were not actually experienced. This can lead to different results, in comparison to the actual experience of negative life events, and engenders the need to examine the evaluations of actual negative life event aversion.

The concept of differentiation of self is intrinsically associated with adolescence. However, in modern society, the age range incorporated into adolescence increases as the duration of schooling increases, and there are delays in leaving home, marrying, and having children [12]. High school age is included in the adolescence category; however, a large portion of adolescents are also university students. Therefore, in Japan, empirical research is required that encompasses both high school students and university students.

\subsection{Study Objectives}

The purpose of this study is twofold. The first purpose was to examine the validity of the differentiation-of-self hypothesis among Japanese university students. If this hypothesis is valid for Japanese university students, those with low self-differentiation who regularly experience negative life events should show some form of maladaptation. The second purpose was to compare the degree of 
self-differentiation with the degree of negative life event aversion actually experienced, to explain part of the mechanism that drives people with low differentiation of self to exhibit maladaptation. If individuals with low self-differentiation tend to overestimate the aversiveness of negative life events, improving cognitive tendencies may be an effective method of intervention.

To this end, a survey was conducted via questionnaire, and two comparisons were made based on the degree of self-differentiation: first, a comparison of maladaptive states, based on the degree of differentiation of self, and second, a comparison of negative life event aversion. This study aimed to contribute to promoting empirical research on the differentiation of self in Japan.

\section{Methods}

\subsection{Sample Size Calculation}

In the $t$-test described below, the effect size (Cohen's $d$ ) was set to $d=0.5$, using the medium-sized effect criteria defined by Cohen [13]. The level of significance was set to $\alpha=0.05$ and the power $(1-\beta)$ was set to 0.8 . Based on these criteria, it was calculated that at least 128 participants were required for the analysis.

\subsection{Participants}

A total of 250 survey participants (147 males, 99 females, 4 unknown) were recruited on a voluntary basis, and comprised university students (age range 19 to 24 years) from the Kanto region of Japan. This study was conducted during the fall semester of the 2017 academic year.

\subsection{Measures}

\subsubsection{Differentiation of Self Scale}

The Differentiation of Self Scale in Two Domains (DSS-2D) [14] was used to examine participants' degrees of differentiation of self. The DSS-2D is a 29-item self-report scale that measures degree of self-differentiation in terms of four subscales: the 10-item Interpersonal Differentiation Togetherness Scale measures whether an individual tends to agree with others, in order to be accepted and to maintain relationships (e.g., I spend a lot of energy trying to get recognized by others); the eight-item Intrapsychic Differentiation Scale measures the balance between thoughts and emotions (e.g., I am able to distinguish emotions and think rationally); the six-item Interpersonal Differentiation Individuality Scale measures an individual's self-will and whether they can act autonomously without being swayed by others' criticism (e.g., I have my own beliefs); and the five-item Adaptive Interpersonal Relationship Scale measures whether an individual is able to manage their interactions with others smoothly, while simultaneously achieving personal goals (e.g., I am able to enjoy interacting with people). Responses are provided on a seven-point Likert scale $(1=$ does not apply at all to $7=$ greatly applies). Some items are reverse scored, and a higher 
score indicates a higher degree of self-differentiation. Note that a higher score on the Interpersonal Differentiation Togetherness Scale indicates a lower desire for togetherness, and individuals with a lower desire for togetherness are considered to be better differentiated. Sufficient reliability and validity have been confirmed for the DSS-2D [14] [15].

\subsubsection{Negative Life Events Scale}

The Scale of Life Events in Interpersonal and Achievement Domains for Undergraduate Students [16] was used to examine negative life event aversion in participants. The scale measures four domains: interpersonal, achievement, irrelevant, and correlation subscales. The subscales measure experiences of events and related emotions in each domain. The scale consists of 119 items and measures both positive and negative life events. Construct validity has been confirmed for the scale [16]. For this study, the subscales were used that correspond to negative life events in the interpersonal domain (NLE-I; 15 items) and achievement domain (NLE-A; 15 items). Participants were asked whether they had experienced each life event listed and, if so, how aversive it was (painful, sad, hard, or disgusting). Responses were provided on a five-point Likert scale $(0=$ did not feel at all to $4=$ felt very strongly). Higher subscale scores reflect higher degrees of aversion related to the domain.

\subsubsection{Maladaptive State Scale}

The General Health Questionnaire (GHQ) [17] is a well-known screening instrument used for the detection of probable non-psychiatric disorders. In this study, the Japanese version of the GHQ-28 [18] was used to examine maladaptive states. The GHQ-28 consists of four subscales; somatic symptoms, anxiety and insomnia, social dysfunction, and severe depression. There are four choices per item, depending on the degree of maladaptation. In this study, degree-dependent choices were assigned between 0 and 3, and the total item scores were taken as the subscale scores. Higher subscale scores reflect higher degrees of maladaptation. Because there is an obvious correlation between differentiation of self and anxiety [1] [3] [14], the anxiety and insomnia scale was excluded from this study.

\subsection{Procedure}

The survey was conducted during lecture periods, from December 2017 to January 2018. The study was explained, both verbally and in writing, on the coversheet, and voluntary participation was established, as well as the ability to withdraw from the research at any time. There were no disadvantages to declining participation. Personal information collected from the questionnaire was protected, and responses to the items were used for research purposes only. Subsequent to the above, the survey was conducted. Consent was implied if an individual completed and returned the questionnaire. This study's design was approved by the ethics review board of the author's university. 


\subsection{Data Analysis}

First, descriptive statistics for all scale scores were calculated, and the participants were divided into two groups, based on the 50th percentile of DSS-2D score distribution (sum total). Next, a $t$-test compared the better- and less-differentiated groups, for maladaptation and negative life event aversion.

\section{Results}

\subsection{Valid Respondents}

The number of valid respondents was 225 ( 134 males, 89 females, 2 unknown). The average age was 20.68 years $(S D=0.83)$. Since the number of females did not exceed the sample size required for this study, analyses were not performed per gender.

\subsection{Descriptive Statistics of Each Scale}

Table 1 shows the mean value and standard deviation of each scale. The floor effect was confirmed on the severe depression scale of the GHQ-28, which was a reasonable result, as the GHQ-28 was developed for screening purposes. The ceiling effect was not seen on any scale.

The cutoff value for grouping was set to 125 , which was the score of the 50th percentile of the distribution for total DSS-2D scores. That is, participants who scored above the 50th percentile (greater than 125) of the distribution on the DSS-2D (sum total), were grouped as better differentiated $(M=139.47, S D=$ 12.52), and those who scored below the 50th percentile (fewer than 125) of the distribution, were grouped as less differentiated $(M=112.14, S D=11.53)$. Of the

Table 1. Scale means and standard deviations.

\begin{tabular}{ccc}
\hline Scale & $M$ & $S D$ \\
\hline Negative Life Events & & \\
NLE-I & 11.91 & 10.39 \\
NLE-A & 15.76 & 9.70 \\
GHQ-28 & & \\
Somatic Symptoms & 8.04 & 4.67 \\
Social Dysfunction & 7.23 & 3.03 \\
Severe Depression & 3.72 & 4.46 \\
DSS-2D & & \\
Interpersonal Differentiation Togetherness & 37.23 & 9.82 \\
Intrapsychic Differentiation & 34.79 & 6.43 \\
Interpersonal Differentiation Individuality & 29.34 & 5.15 \\
Adaptive Interpersonal Relationship & 24.74 & 5.00 \\
Sum total & 126.11 & 18.22 \\
\hline
\end{tabular}

Note. $N=225$ 
225 participants, 115 were in the better-differentiated group and 110 were in the less-differentiated group.

\subsection{Maladaptive States}

The $t$-test revealed significantly higher maladaptive state scores (GHQ-28 scores) for the less-differentiated group than for the better-differentiated group (Table 2). Cohen's $d$ ranged from 0.36 to 0.54 , and the differences in effect size were small to moderate (severe depression was the largest). This suggested that the differentiation-of-self hypothesis is also valid for Japanese university students.

\subsection{Aversiveness of Negative Life Events}

The $t$-test revealed significantly higher NLE-I and NLE-A scores for the lessdifferentiated group than for the better-differentiated group (Table 3 ). This suggested that those who are less differentiated tend to feel greater negative life event aversion, in both the interpersonal and achievement domains. Cohen's $d$ was 0.53 (NLE-I) and 0.51 (NLE-A). These differences were similar and moderate in effect size. This suggested that those who are less differentiated perceive negative life events as more aversive, irrelevant of the domain.

\section{Discussion}

\subsection{The Validity of the Differentiation-of-Self Hypothesis among Japanese University Students}

The primary purpose of this study was to examine the validity of the differentiation-of-self hypothesis among Japanese university students. The results showed

Table 2. Differences between better- and less-differentiated groups in maladaptive states

\begin{tabular}{|c|c|c|c|c|c|c|c|c|}
\hline \multirow[t]{2}{*}{ Subscale } & \multicolumn{2}{|c|}{$\begin{array}{l}\text { Better-differentiate } \\
\text { d group }(N=115)\end{array}$} & \multicolumn{2}{|c|}{$\begin{array}{l}\text { Less-differentiated } \\
\text { group }(N=110)\end{array}$} & \multirow[t]{2}{*}{$t$} & \multirow{2}{*}{$d f$} & \multirow{2}{*}{$p$} & \multirow{2}{*}{$\begin{array}{c}\text { Cohen's } \\
d\end{array}$} \\
\hline & $M$ & $S D$ & $M$ & $S D$ & & & & \\
\hline Somatic Symptoms & 7.23 & 4.54 & 8.88 & 4.67 & -2.70 & 223 & 0.008 & 0.36 \\
\hline Social Dysfunction & 6.59 & 2.66 & 7.90 & 3.24 & -3.30 & $211.00^{\mathrm{a}}$ & 0.001 & 0.44 \\
\hline Severe Depression & 2.57 & 3.82 & 4.92 & 4.76 & -4.08 & $208.78^{\mathrm{a}}$ & $<0.001$ & 0.54 \\
\hline
\end{tabular}

Note. ${ }^{a}$ Welch's $t$-test.

Table 3. Differences between better- and less-differentiated groups for negative life event aversion.

\begin{tabular}{|c|c|c|c|c|c|c|c|c|}
\hline \multirow{2}{*}{ Domain } & \multicolumn{2}{|c|}{$\begin{array}{c}\text { Better-differentiate } \\
\text { d group }(N=115)\end{array}$} & \multicolumn{2}{|c|}{$\begin{array}{l}\text { Less-differentiated } \\
\text { group }(N=110)\end{array}$} & \multirow[t]{2}{*}{$T$} & \multirow{2}{*}{$d f$} & \multirow{2}{*}{$p$} & \multirow{2}{*}{$\begin{array}{c}\text { Cohen's } \\
d\end{array}$} \\
\hline & $M$ & $S D$ & $M$ & $S D$ & & & & \\
\hline $\begin{array}{l}\text { Interpersonal domain } \\
\text { (NLE-I) }\end{array}$ & 9.31 & 9.38 & 14.63 & 10.73 & -3.96 & 223 & $<0.001$ & 0.53 \\
\hline $\begin{array}{c}\text { Achievement domain } \\
\text { (NLE-A) }\end{array}$ & 13.41 & 8.73 & 18.22 & 10.08 & -3.83 & 223 & $<0.001$ & 0.51 \\
\hline
\end{tabular}


that the less-differentiated group had significantly higher maladaptive state scores than the better-differentiated group. This suggested that the differentiation-of-self hypothesis is also valid for Japanese university students. The results of this study may provide a basis for the differentiation-of-self hypothesis, which is currently empirically accepted as one of the fundamental hypotheses in the clinical practice of family therapy in Japan.

This study used three indicators (somatic symptoms, social dysfunction, and severe depression) to validate the differentiation-of-self hypothesis, which was subsequently supported by all the results. Among them, the effect size of severe depression was the largest; therefore, depression may be one of the primary maladaptive states affected by degree of differentiation of self.

\subsection{The Mechanism of Less-Differentiated Individuals' Negative Life Event Vulnerability}

The second purpose of this study was to examine the relationship between degree of differentiation of self and negative life event aversion, to explain part of the mechanism by which individuals with low self-differentiation exhibit maladaptive states. The results showed that the less-differentiated group experienced greater negative life event aversion than the better-differentiated group. This was a common result, regardless of the negative life event domain, indicating that, compared to those who are better differentiated, less-differentiated individuals may tend to perceive various negative life events as more aversive, be more susceptible to negative life events, and eventually exhibit certain maladaptive states. This explains part of the mechanism of negative life event vulnerability in those who are less differentiated, in terms of negative life event aversion.

Kudo and Fujiu [11] obtained a similar result in a survey of high school students, but also included negative life events that participants did not actually experience. However, in this study, responses included only those negative life events that were actually experienced, and no response was required regarding the aversiveness of negative life events that were not actually experienced. Therefore, the results are based on the actual experience of each negative life event. In this regard, the findings of this study are more realistic than the results of Kudo and Fujiu [11].

\subsection{Differences in Negative Life Event Aversion by Domain}

In this study, regardless of the degree of differentiation of self, negative life events were more aversive in the achievement domain than in the interpersonal domain. This may be due to the influence of the survey period. During this period, students tended to experience negative life events in the achievement domain, as it corresponded with credit acquisition and transition to the next grade. Therefore, for students, negative life events in the achievement domain were more realistic and imminent.

Originally, it was presumed that negative life events in the interpersonal domain were more related to degree of differentiation of self than in the achieve- 
ment domain [9] [11]. However, during this period, negative life events in the achievement domain were perceived relatively strongly and, as a result, there may have been no differences between the domains in this study.

\subsection{Effectiveness of Cognitive Intervention in Less-Differentiated Individuals}

The results of this study showed that, compared with the better-differentiated group, the less-differentiated group had higher maladaptive state scores, with depression being the highest. Kudo and Fujiu [11] showed that differentiation of self and depressive schema are negatively correlated. Therefore, depressive schema may be one of the factors that influence depression in less-differentiated individuals. Additionally, compared to the better-differentiated group, the less-differentiated group was shown to regard negative life events as more aversive. According to Lazarus and Folkman's [10] framework, the less-differentiated group's cognitive tendencies toward negative life events led to higher maladaptive state scores.

The above suggests that cognitive intervention may be effective in reducing the vulnerability to negative life events of less-differentiated individuals. This is because cognitive interventions, such as cognitive therapy [19] [20] [21], are effective in ameliorating depressive schema, thus improving cognitive tendencies toward negative life events.

Until now, several years of therapy, such as with genograms, were needed to ameliorate various maladaptive states resulting from low levels of differentiation of self [9]. Such therapies have primarily dealt with the relationship between oneself and one's family of origin [1] [3]. However, maladaptation itself, such as depression, may be improved by intervening in individuals' cognitive aspects. In other words, a less-differentiated individual may improve the symptoms themselves, without having to spend years addressing family-related issues in therapy.

\section{Conclusion}

This study found that the differentiation-of-self hypothesis is also valid for Japanese university students. In particular, depressive states are susceptible to degree of differentiation of self. Furthermore, the results showed that less-differentiated individuals, more than better-differentiated individuals, tend to perceive negative life events as more aversive. This cognitive tendency may be a part of the mechanism of vulnerability to negative life events. Therefore, improving less-differentiated individuals' cognitive tendencies may be effective for interventions to decrease maladaptive states, such as depression.

\section{Limitations and Future Challenges}

This study's limitations and proposed future challenges are discussed below.

The experience of negative life events was not well controlled, occurring mainly by chance, and the particular situations that participants recalled varied for each item of the negative life event scale. Therefore, it is hard to say that the 
evaluation of degree of aversiveness reflected only the cognitive tendencies of each participant, because some may have been influenced by the specificities of recalled situations. Additionally, because of the degree of aversiveness, less-differentiated individuals may avoid negative life events in the interpersonal domain as much as possible. This study did not measure negative life event aversion that was not directly experienced. Therefore, a scale is required that further clarifies the specific situations of negative life events, and targets only individuals with experiences with each of the scale's listed negative life events.

Although many studies on differentiation of self [6] [22] [23] show gender differences, this study did not analyze data by gender, due to the insufficient number of females. Evaluating negative life event aversion is only part of the overall mechanism of maladaptive states. Future studies should consider other variables in the mechanism, including gender differences.

\section{Acknowledgements}

This work was supported by JSPS KAKENHI Grant Number JP16K04294.

\section{Conflicts of Interest}

The author declares no conflicts of interest regarding the publication of this paper.

\section{References}

[1] Bowen, M. (1978) Family Therapy in Clinical Practice. Jason Aronson, Lanham.

[2] Von Bertalanffy, L. (1968) General System Theory: Foundations, Development, Applications. Georges Braziller, Inc., New York.

[3] Kerr, M.E. and Bowen, M. (1988) Family Evaluation: An Approach Based on Bowen Theory. W.W. Norton and Company, New York.

[4] Jankowski, P.J., Hooper, L.M., Sandage, S.J. and Hannah, N.J. (2013) Parentification and Mental Health Symptoms: Mediator Effects of Perceived Unfairness and Differentiation of Self. Journal of Family Therapy, 35, 43-65. https://doi.org/10.1111/j.1467-6427.2011.00574.x

[5] Lampis, J. (2016) Does Partners' Differentiation of Self Predict Dyadic Adjustment? Journal of Family Therapy, 38, 303-318. https://doi.org/10.1111/1467-6427.12073

[6] Peleg, O. and Yitzhak, M. (2011) Differentiation of Self and Separation Anxiety: Is There a Similarity between Spouses? Contemporary Family Therapy, 33, 25-36. https://doi.org/10.1007/s10591-010-9137-Z

[7] Xue, Y., Xu, Z., Zaroff, C., Chi, P., Du, H., Ungvari, G.S., et al. (2018) Associations of Differentiation of Self and Adult Attachment in Individuals with Anxiety-Related Disorders. Perspectives in Psychiatric Care, 54, 54-63. https://doi.org/10.1111/ppc. 12200

[8] Havighurst, R.J. (1948) Developmental Tasks and Education. Longmans, Green, New York

[9] Yusa, Y. (1984) Systems Approach in Family Therapy: Overview of Theory and Practice. Seiwa Shoten Co., Ltd., Tokyo.

[10] Lazarus, R.S. and Folkman, S. (1984) Stress, Appraisal, and Coping. Springer Pub- 
lishing Company, Berlin.

[11] Kudo, K. and Fujiu, H. (2012) The Influence of Differentiation of Self on Aversiveness for Negative Life Events among High School Students. Japanese Journal of Personality, 21, 99-110. https://doi.org/10.2132/personality.21.99

[12] Smith, P.K. (2016) Adolescence: A Very Short Introduction. Oxford University Press, Oxford. https://doi.org/10.1093/actrade/9780199665563.001.0001

[13] Cohen, J. (1988) Statistical Power Analysis for the Behavioral Sciences. 2nd Edition, L. Erihaum Associates, New York.

[14] Kudo, K. (2018a) A Differentiation of Self Scale in Two Domains for Japan: A Preliminary Study on Its Development and Reliability/Validity. Psychology, 9, 745-759. https://doi.org/10.4236/psych.2018.94047

[15] Kudo, K. (2018b) An Additional Consideration of Reliability and Validity of the Differentiation of Self Scale in Two Domains. Psychology, 9, 2411-2421. https://doi.org/10.4236/psych.2018.910138

[16] Takahira, M. (1998) Construction of a Scale of Life Events in Interpersonal and Achievement Domains for Undergraduate Students. Research in Social Psychology, 14, 12-24.

[17] Goldberg, D. (1978) Manual of the General Health Questionnaire. Nfer Nelson, Windsor.

[18] Nakagawa, Y. and Daibo, I. (2013) Japanese Version of the General Health Questionnaire Manual. Expanded Edition, Nihon Bunka Kagakusha Co., Ltd., Tokyo.

[19] Beck, A.T. (1976) Cognitive Therapy and the Emotional Disorders. Penguin, London.

[20] DeRubeis, R.J., Keefe, J.R. and Beck, A.T. (2019) Cognitive Therapy. In: Dobson, K.S. and Dozois, D.J.A., Eds., Handbook of Cognitive-Behavioral Therapies, 4th Edition, The Guilford Press, New York, 218-248.

[21] Young, J.E., Rygh, J.L., Weinberger, A.D. and Beck, A.T. (2014) Cognitive Therapy for Depression. In: Barlow, D.H., Ed., Clinical Handbook of Psychological Disorders. A Step-by-Step Treatment Manual, 5th Edition, The Guilford Press, New York, 275-331.

[22] Lampis, J., Cataudella, S., Agus, M., Busonera, A. and Skowron, E.A. (2019) Differentiation of Self and Dyadic Adjustment in Couple Relationships: A Dyadic Analysis Using the Actor-Partner Interdependence Model. Family Process, 58, 698-715. https://doi.org/10.1111/famp.12370

[23] Peleg, O. (2014) The Relationships between Stressful Life Events during Childhood and Differentiation of Self and Intergenerational Triangulation in Adulthood. International Journal of Psychology, 49, 462-470. https://doi.org/10.1002/ijop.12054 